\title{
The Burden of Chronic Urticaria from Brazilian Patients' Perspective
}

\author{
Maria-Magdalena Balp · Nilcéia Lopes da Silva · Jeffrey Vietri • \\ Haijun Tian · Luis F. Ensina
}

Received: May 4, 2017 / Published online: July 26, 2017

(C) The Author(s) 2017. This article is an open access publication

\begin{abstract}
Introduction: Chronic urticaria (CU), a proxy for chronic spontaneous urticaria, has been associated with a negative impact on health-related quality of life (HRQoL) and costs, but there is limited evidence on the burden of $\mathrm{CU}$ in Brazil. The objective of this study was to estimate the prevalence of $\mathrm{CU}$ and assess the burden of $\mathrm{CU}$ on HRQoL and healthcare resource utilization (HRU) among adults in Brazil.
\end{abstract}

The original version of this article was revised: In the original publication, fifth author's name was incorrectly published as Luis F. Esina. The correct name should read as 'Luis F. Ensina'.

Enhanced content To view enhanced content for this article go to http://www.medengine.com/Redeem/ 2CD8F06011DD33BC.

M.-M. Balp ( $\square)$

Novartis Pharma AG, Basel, Switzerland

e-mail: maria-magdalena.balp@novartis.com

N. Lopes da Silva

Novartis Biociências S.A., São Paulo, Brazil

J. Vietri

Kantar Health, Horsham, PA, USA

H. Tian

Novartis Pharmaceutical Corporation, Global

Medical Affairs, East Hanover, NJ, USA

L. F. Ensina

Federal University of São Paulo, São Paulo, Brazil
Methods: This retrospective, cross-sectional study, pooled data from the 2011, 2012, and 2015 National Health and Wellness Survey in Brazil $\quad(n=36,000)$. Respondents (aged $\geq 18$ years) diagnosed with and treated for $\mathrm{CU}$ provided data on demographics, health history, HRQoL (mental and physical health status) on Short-Form SF-36v2, presence of psychological complaints, work impairment, activity impairment, and HRU. Generalized linear models, controlling for covariates, examined differences between those treated for $\mathrm{CU}$ and matched controls on the outcome variables.

Results: The prevalence of diagnosed CU was $0.41 \%(n=249)$ and treated CU was $0.21 \%$ $(n=127)$. After adjustments, CU (currently treated for $\mathrm{CU}$ ) was associated with worse mental functioning, physical functioning, and health utilities compared with controls (all $p<0.01)$. CU had over twice the odds of anxiety and sleep difficulties, over 1.5 times the work and activity impairment, twice the number of total physician visits, eight times the number of allergist visits, and twice the number of emergency room visits as controls (all $p<0.01$ ).

Conclusions: Many CU patients using prescription treatment experienced anxiety and sleep disturbances, poorer HRQoL, significant work and activity impairment, and high HRU, compared with matched general population controls. Findings suggest an unmet need for more effective treatment and management of CU in Brazil. Funding: Novartis Pharma AG and Genentech. 
Keywords: Chronic urticaria; Prevalence; Productivity impairment; Quality of life; Resource utilization

\section{INTRODUCTION}

Urticaria is a disease characterized by wheals (hives), which are accompanied by itching or burning sensations, and/or angioedema [1]. When these symptoms last at least 6 weeks, the disease is considered chronic [2]. Chronic urticaria (CU) can be classified into chronic spontaneous/idiopathic urticaria (CSU/CIU) and chronic inducible urticaria $[1,2]$. CU has no identifiable trigger, and symptoms and signs can be unpredictable $[1,2]$. The peak incidence is between 20 and 40 years of age, and prevalence is higher among women than men [3-9]. The average duration of $\mathrm{CU}$ is generally $1-5$ years, but varies from a few months to well over a decade [3].

The point prevalence of $\mathrm{CU}$ has been estimated to range from 0.1 to $1.0 \%[4,10]$, with recent studies reporting the diagnosed prevalence of $\mathrm{CU}$ to be $0.53 \%$ in the United States (US) [5] and $0.63 \%$ across five major European countries [6].

Although not life threatening, CU, including CSU/CIU, has been associated with a negative impact on different aspects of patients' health-related quality of life (HRQoL) [11]. For example, previous research found this condition related to an increased prevalence of anxiety and depression $[5,6,12]$, greater impairment in work and daily activities, and with negative consequences on healthcare providers and society $[5,6,12,13]$. Furthermore, patients with urticaria tend to report higher overall work productivity impairment than those with pruritus or psoriasis, as well as higher classroom productivity impairment than those with atopic dermatitis or eczema [14].

Despite its substantial impact on patient HRQoL and social costs, the prevalence of CU and evidence about the economic and humanistic burden associated with CU in the Brazilian population is limited. Thus, the objectives of this research study were to assess the prevalence and the burden of illness, as defined by HRQoL, psychological complaints, work impairment, impairment or disruption of non-work activities, and the use of healthcare resources, among the adult Brazilian population who self-reported current treatment for CU (used as a proxy for CSU).

\section{METHODS}

\section{Study Design and Sample}

This study was a retrospective, cross-sectional analysis, using an existing database of survey responses from the National Health and Wellness Survey (NHWS) in Brazil. The NHWS includes questions asking about the experience, diagnosis, and treatment of chronic hives (CU), which we used as a close approximate for CSU (accordingly, going forward, we refer to chronic hives as $\mathrm{CU})$. Using $\mathrm{CU}$ as a proxy for CSU is consistent with the approach employed by previous studies with NHWS data $[5,6,15]$. Further, more than two-thirds of cases of CU can be classified as CSU (estimates ranging between 66\% and 93\%) [3]. Potential respondents of the NHWS were identified primarily through participation in opt-in online survey panels, with stratified random sampling within the survey panel to ensure representativeness of the Brazilian population in terms of age and gender. The current project used data collected in 2011, 2012, and 2015 (the NHWS did not collect data in 2013 and 2014 in Brazil). Respondents were required to be at least 18 years of age, able to understand Portuguese, and provide informed consent. All procedures performed in studies involving human participants were in accordance with the ethical standards of the Essex Institutional Review Board (Lebanon, NJ, USA), and the Pearl Institutional Review Board (Indianapolis, IN, USA), and with the 1964 Helsinki declaration and its later amendments or comparable ethical standards. For this type of study, formal consent was not required.

\section{Measures}

\section{Chronic Urticaria}

The proportions of the adult Brazilian population in the NHWS who reported having ever experienced $\mathrm{CU}$, reported a physician diagnosis 
of $\mathrm{CU}$, and reported current treatment for this condition were individually evaluated. Respondents who reported current treatment were compared with controls (i.e., those who did not report ever experiencing chronic hives). Respondents who had either experienced or were diagnosed with the condition, but not currently being treated, were excluded from the analyses.

\section{Sociodemographics and General Health Characteristics}

Several sociodemographic characteristics were assessed in the NHWS: age, sex, race, employment status (yes/no), annual household income (below median vs. above median vs. decline to answer), marital status (married or living with partner vs. not), level of education (university education or higher vs. less than a university education), and type of health insurance (public vs. private). Socio-economic status was also assessed using a reference measure developed by the Associação Brasileira de Anunciantes, Associação Brasileira dos Institutos de Pesquisa de Mercado, and Associação Nacional de Empresas de Pesquisa de Mercado [16]. According to this classification, social classes are stratified as a function of household comfort (presence of electronic equipment, cars, and housekeeper) and the level of education of the head of the household. Based on the total punctuation (from 0 to 46), there are eight levels of socio-economic classification (A1: $42-46$ points; A2: 35-41 points; B1: 29-34; B2: 23-28; C1: 18-22; C2: 14-17; D: 8-13 and E: 0-7) [16]. Also, body mass index (BMI) was calculated from self-reported height and weight and categorized as underweight $\left(<18.5 \mathrm{~kg} / \mathrm{m}^{2}\right)$, normal weight (18.5 to $<25.0 \mathrm{~kg} / \mathrm{m}^{2}$ ), overweight $(25.0$ to $\left.<30.0 \mathrm{~kg} / \mathrm{m}^{2}\right)$, obese $\left(30.0 \mathrm{~kg} / \mathrm{m}^{2}\right.$ and above), or decline to answer. Cigarette smoking (current vs. former vs. never), frequency of alcohol use (none vs. less than daily vs. daily), and whether the respondent reported vigorous exercise in the past 30 days (yes vs. no) were measured. To assess comorbid burden, respondents answered questions from the Charlson Comorbidity Index (CCI) [17]. The CCI sums and weights the presence of several different diseases and disorders, such that the greater the total index score, the greater the comorbid burden on the patient.

\section{HRQoL}

Health status was assessed in 2010 and 2011 using questions from the Medical Outcomes Study 12-Item Short Form Survey Instrument Version-2 (SF-12v2), which is a multipurpose, generic health status instrument comprised of 12 questions; the longer SF-36v2 was used in the 2015 NHWS $[18,19]$. These instruments provide two summary scores: the mental component summary (MCS) and the physical component summary (PCS). The MCS includes questions related to role limitations caused by emotional problems, vitality, social functioning, and mental health. The PCS includes questions related to physical functioning, bodily pain, and general physical health. Higher scores represent better HRQoL. The Short Form-6 Dimension health utility score (SF-6D), which was calculated from the SF-12v2/SF-36v2, is a preference-based measure of HRQoL (i.e., health utility score approximately ranging from 0 to 1) [20, 21]. Again, higher score represents better HRQoL.

\section{Psychological Complaints}

NHWS respondents reported if they had experienced anxiety, depression, and sleep problems in the past 12 months.

\section{Work Productivity and Activity Impairment}

Labor force participation was measured by self-reported employment status. Respondents were considered to be in the labor force if employed full-time, part-time, self-employed, or unemployed but looking for work; all others were considered not to be in the labor force (retired, disabled, not employed, and not looking for work, etc.). Work productivity impairment during the past seven days was assessed using the General Health version of the Work Productivity and Activity Impairment questionnaire (WPAI-GH) [22]. This instrument measures absenteeism (the percentage of work time missed because of health), presenteeism (the percentage of impairment experienced while at work because of one's health), and overall work productivity loss (an overall impairment estimate combining absenteeism and presenteeism), among employed respondents. Activity impairment (the percentage of impairment in daily 
activities because of health) was assessed in the full sample of participants.

\section{Healthcare Resource Use}

Healthcare resource use was defined by the number of visits to different medical providers during the prior six months due to any cause, including visits to physicians and other healthcare professionals, use of the emergency room (ER) and hospitalizations.

\section{Statistical Analyses}

Prevalence estimates of $\mathrm{CU}$ were based on the proportion of the adult population who (1) reported ever experiencing this condition, (2) reported having received a physician diagnosis, and (3) were currently being treated for this condition, by applying weights based on age (18-29, 30-39, 40-49, 50-64, and 65+ years) and gender figures from 2012 (https://www. census.gov/population/international/).

To assess the impact of $\mathrm{CU}$ on individuals, respondents who were currently treated for this condition were matched 1:4 with those who reported never experiencing CU on year of survey, age ( \pm 2 years), sex, possession of private health insurance, and socioeconomic status. This was followed by regression analyses using generalized linear models, with race (white vs. non-white), household income (above median, below median, or decline to answer), smoking (current, former, or never), obesity, and CCI score (continuous variable) used as covariates. Variables that were measured, but did not differ across groups, were not included as covariates. The HRQoL outcomes were modeled using the normal distribution and identity link function. Binary outcomes were modeled using logistic regression. All other outcomes were modeled using a negative binomial distribution and log-link function.

\section{RESULTS}

\section{Prevalence}

For the overall sample $(n=36,000), 320$ reported having ever experienced $\mathrm{CU}, 249$ reported having ever been diagnosed with $\mathrm{CU}$, and 127 respondents reported current treatment for this condition. This corresponds to an estimated point prevalence of $0.53,0.41$ and $0.21 \%$, respectively. CU was also found to be more common among women than men. Prevalence was lowest among the elderly (65+ years) and highest in the 45- to 54-year age group (Tables 1, 2).

\section{Comparison of CU with Controls}

Of the 36,000 total respondents, 127 reported current treatment for $\mathrm{CU}$ and 508 matched controls were included in the analyses. Most personal characteristics did not differ across the matched groups, but the mean CCI score was notably more elevated among CU $(p<0.001)$, indicating that these participants reported a greater comorbidity burden than controls. Smoking status also significantly differed between groups $(p=0.015)$, as the $\mathrm{CU}$ respondents were more likely to be current smokers than controls. There was a non-significant trend for the CU group to more often report being of white race/ethnicity than controls $(p=0.093)$ (Table 3).

\section{HRQoL}

In the bivariate analyses for matched comparisons, CU respondents had notably lower MCS, PCS, and SF-6D health utility scores (all $p<0.001$ ) (Fig. 1). In the regression analyses, after adjustment, decrements associated with CU were 5 points for MCS, 2.5 points for PCS, and 0.06 points for SF-6D (all $p<0.01$ ), confirming that $\mathrm{CU}$ negatively impacts HRQoL.

\section{Psychological Complaints}

In the bivariate analyses for matched comparisons, rates of anxiety, depression, and sleep difficulties were almost double the rate for $\mathrm{CU}$ respondents compared with controls (all $p<0.001$ (Table 4). In the regression analyses, after adjusting for race/ethnicity, comorbidities, and smoking, CU was associated with more than twice the adjusted odds of experiencing anxiety and sleep difficulties (both $p<0.001$ ). However, the increased odds of experiencing 
Table 1 Prevalence estimate of CU in all Brazilian adults and by gender

\begin{tabular}{llll}
\hline Variables & \multicolumn{2}{l}{ Prevalence estimate (95\% CI) } & \\
\cline { 2 - 4 } & Overall (\%) & Men (\%) & Women (\%) \\
\hline Ever experienced & $0.53(0.44-0.62)$ & $0.41(0.29-0.53)$ & $0.64(0.52-0.77)$ \\
Ever diagnosed & $0.41(0.33-0.49)$ & $0.32(0.21-0.43)$ & $0.50(0.39-0.61)$ \\
Currently treated & $0.21(0.15-0.27)$ & $0.16(0.08-0.25)$ & $0.25(0.15-0.34)$ \\
\hline
\end{tabular}

$C I$ confidence interval, $C U$ chronic urticaria

Table 2 Prevalence estimate of $\mathrm{CU}$ in all Brazilian adults by age groups

\begin{tabular}{|c|c|c|c|c|c|c|c|c|c|}
\hline \multirow[t]{2}{*}{ Age (years) } & \multicolumn{3}{|c|}{ Currently treated } & \multicolumn{3}{|c|}{ Ever diagnosed } & \multicolumn{3}{|c|}{ Ever experienced } \\
\hline & $\%$ & 95\% LCL & 95\% UCL & $\%$ & $95 \% \mathrm{LCL}$ & 95\% UCL & $\%$ & 95\% LCL & 95\% UCL \\
\hline $18-24$ & 0.17 & 0.09 & 0.25 & 0.27 & 0.16 & 0.37 & 0.32 & 0.21 & 0.43 \\
\hline $25-34$ & 0.18 & 0.12 & 0.24 & 0.43 & 0.28 & 0.57 & 0.59 & 0.43 & 0.75 \\
\hline $35-44$ & 0.31 & 0.12 & 0.51 & 0.53 & 0.32 & 0.74 & 0.64 & 0.42 & 0.87 \\
\hline $45-54$ & 0.31 & 0.08 & 0.55 & 0.61 & 0.35 & 0.88 & 0.74 & 0.46 & 1.02 \\
\hline $55-64$ & 0.12 & 0.04 & 0.21 & 0.32 & 0.15 & 0.48 & 0.53 & 0.28 & 0.77 \\
\hline 65 and older & 0.03 & 0.00 & 0.06 & 0.10 & 0.00 & 0.25 & 0.11 & 0.00 & 0.25 \\
\hline
\end{tabular}

$L C L$ lower confidence limit, $U C L$ upper confidence limit, $C U$ chronic urticaria

depression for $\mathrm{CU}$ no longer reached significance $(p=0.060)$.

\section{Work Productivity and Activity Impairment}

In the bivariate analyses for matched comparisons, employed CU respondents reported higher presenteeism and overall work impairment scores, compared with controls (both $p<0.001$ ) (Table 5). Similarly, activity impairment was also significantly higher among CU relative to controls $(p<0.001)$. The regression analyses showed CU was associated with 1.5-1.6 times the work and activity impairment of controls, after adjusting for potential confounders (all $p<0.01)$.

\section{Healthcare Resource Use}

In the bivariate analyses for matched comparisons, much more frequent healthcare resource use was reported among those with $\mathrm{CU}$ than controls (Table 6). Specifically, the total number of health care provider visits in the previous six months for CU respondents averaged approximately 2.4 times that of controls $(p<0.001)$. In the regression analyses, after adjustment, CU was associated with twice the number of total healthcare provider visits, eight times the number of allergist visits, and twice the number of ER visits compared with controls (all $p<0.01$ ).

\section{DISCUSSION}

The results of the current study showed that, in Brazil, adults with CU have substantially worse outcomes than people living without $\mathrm{CU}$, including HRQoL decrements, anxiety, and sleep difficulties. CU was also associated with significant impairments on work and non-work activities and greatly elevated healthcare resource use.

The prevalence of diagnosed CU among adults in Brazil in this study was similar to what has been reported in prior studies in the US and Europe. However, the prevalence of treated CU 
Table 3 Patient characteristics in controls and CU respondents after matching

\begin{tabular}{|c|c|c|c|c|c|}
\hline & \multicolumn{2}{|c|}{$\begin{array}{l}\text { Controls } \\
(n=508)\end{array}$} & \multicolumn{2}{|c|}{$\begin{array}{l}\mathrm{CU} \\
(n=127)\end{array}$} & \multirow[t]{2}{*}{$p$ value } \\
\hline & $\begin{array}{l}n / \\
\text { Mean }\end{array}$ & $\begin{array}{l}\% / \\
\text { SD }\end{array}$ & $\begin{array}{l}n / \\
\text { Mean }\end{array}$ & $\begin{array}{l}\% / \\
\text { SD }\end{array}$ & \\
\hline $\begin{array}{l}\text { Age, years } \\
\qquad(\text { Mean, SD) }\end{array}$ & 37.1 & 11.7 & 37.1 & 11.8 & 0.982 \\
\hline Female & 328 & $64.6 \%$ & 82 & $64.6 \%$ & 1.000 \\
\hline White & 345 & $67.9 \%$ & 96 & $75.6 \%$ & 0.093 \\
\hline Employed & 381 & $75.0 \%$ & 97 & $76.4 \%$ & 0.748 \\
\hline $\begin{array}{c}\text { Married/living } \\
\text { w/partner }\end{array}$ & 286 & $56.3 \%$ & 76 & $59.8 \%$ & 0.471 \\
\hline $\begin{array}{l}\text { Completed } \\
\text { university }\end{array}$ & 262 & $51.6 \%$ & 60 & $47.2 \%$ & 0.383 \\
\hline $\begin{array}{l}\text { Socioeconomic } \\
\text { status }\end{array}$ & & & & & 0.999 \\
\hline $\mathrm{A} 1 / 2$ & 102 & $20.1 \%$ & 26 & $20.5 \%$ & \\
\hline B1 & 180 & $35.4 \%$ & 45 & $35.4 \%$ & \\
\hline B2 & 157 & $30.9 \%$ & 39 & $30.7 \%$ & \\
\hline $\mathrm{C} 1$ & 62 & $12.2 \%$ & 15 & $11.8 \%$ & \\
\hline C2-E & 7 & $1.4 \%$ & 2 & $1.6 \%$ & \\
\hline $\begin{array}{l}\text { Private health } \\
\text { insurance }\end{array}$ & 370 & $72.8 \%$ & 93 & $73.2 \%$ & 0.929 \\
\hline $\begin{array}{l}\text { Median split, } \\
\text { reported } \\
\text { household } \\
\text { income }\end{array}$ & & & & & 0.186 \\
\hline Lower income & 154 & $30.3 \%$ & 30 & $23.6 \%$ & \\
\hline $\begin{array}{l}\text { Higher } \\
\text { income }\end{array}$ & 303 & $59.6 \%$ & 87 & $68.5 \%$ & \\
\hline $\begin{array}{l}\text { Decline to } \\
\text { answer }\end{array}$ & 51 & $10.0 \%$ & 10 & $7.9 \%$ & \\
\hline $\begin{array}{l}\text { CCI } \\
\text { (Mean, SD) }\end{array}$ & 0.31 & 0.74 & 1.43 & 3.51 & $<0.001$ \\
\hline BMI categories & & & & & 0.122 \\
\hline Underweight & 13 & $2.6 \%$ & 7 & $5.5 \%$ & \\
\hline Normal & 252 & $49.6 \%$ & 49 & $38.6 \%$ & \\
\hline
\end{tabular}

Table 3 continued

\begin{tabular}{|c|c|c|c|c|c|}
\hline & \multicolumn{2}{|c|}{$\begin{array}{l}\text { Controls } \\
(n=508)\end{array}$} & \multicolumn{2}{|c|}{$\begin{array}{l}\mathrm{CU} \\
(n=127)\end{array}$} & \multirow[t]{2}{*}{$p$ value } \\
\hline & $\begin{array}{l}n / \\
\text { Mean }\end{array}$ & $\begin{array}{l}\% / \\
\text { SD }\end{array}$ & $\begin{array}{l}n / \\
\text { Mean }\end{array}$ & $\begin{array}{l}/ \\
\text { SD }\end{array}$ & \\
\hline Overweight & 142 & $28.0 \%$ & 42 & $33.1 \%$ & \\
\hline Obese & 94 & $18.5 \%$ & 28 & $22.0 \%$ & \\
\hline $\begin{array}{l}\text { Decline to } \\
\text { answer }\end{array}$ & 7 & $1.4 \%$ & 1 & $0.8 \%$ & \\
\hline Smoking status & & & & & 0.015 \\
\hline Current & 84 & $16.5 \%$ & 35 & $27.6 \%$ & \\
\hline Former & 116 & $22.8 \%$ & 28 & $22.0 \%$ & \\
\hline Never & 308 & $60.6 \%$ & 64 & $50.4 \%$ & \\
\hline Alcohol use & & & & & 0.175 \\
\hline Daily & 13 & $2.6 \%$ & 3 & $2.4 \%$ & \\
\hline $\begin{array}{l}\text { Less than } \\
\text { daily }\end{array}$ & 311 & $61.2 \%$ & 89 & $70.1 \%$ & \\
\hline None & 184 & $36.2 \%$ & 35 & $27.6 \%$ & \\
\hline Exercises & 329 & $64.8 \%$ & 84 & $66.1 \%$ & 0.771 \\
\hline
\end{tabular}

$B M I$ body mass index, $C C I$ Charlson comorbidity index, $C U$ chronic urticaria, $S D$ standard deviation

in this study was somewhat lower than what has been reported in the US and Europe. In particular, estimates have ranged from 0.5 to $1.0 \%$ in US and European adult populations [4-6]. Despite these very modest differences in prevalence estimates, the results of the current study support findings from similar research conducted with participants in other geographies.

With respect to HRQoL and healthcare resource use, the current study found lower HRQoL scores and greater healthcare resource use for those with CU than for controls. Similar associations were found among adults in the US and five European nations [5, 6]. Nevertheless, it is possible that HRQoL and other outcomes may be different among patients with CU in Brazil, relative to those in the US or Europe, given the substantial differences in socioeconomic status between populations in developing nations, 

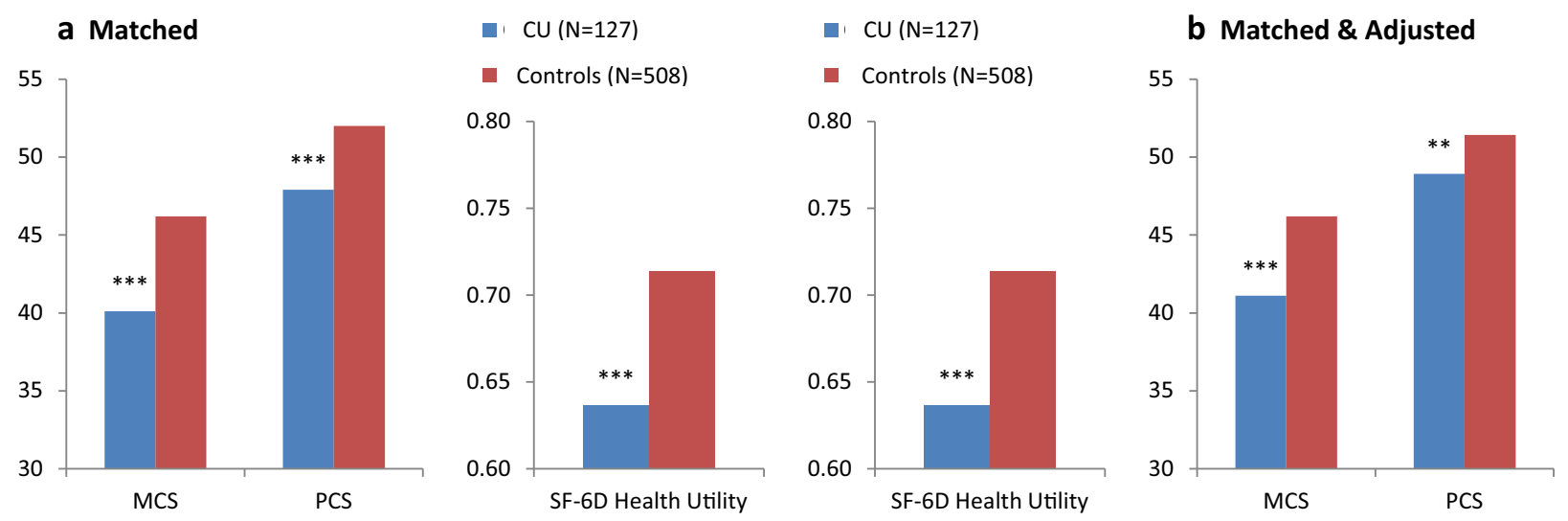

Fig. 1 HRQoL by CU in a matched comparisons and $\mathbf{b}$ matched and adjusted comparisons. $C U$ chronic urticaria, $M C S$ mental component summary, PCS physical component summary; ${ }^{* *} p<0.01 ;{ }^{* * *} p<0.001$

Table 4 Proportion and adjusted odds of psychological complaints among CU respondents relative to controls

\begin{tabular}{|c|c|c|c|c|c|}
\hline & \multicolumn{3}{|l|}{ Matched comparisons } & \multicolumn{2}{|c|}{$\begin{array}{l}\text { Regression estimates for } \\
\text { CU relative to controls }\end{array}$} \\
\hline & $\begin{array}{l}\text { Controls }(\mathrm{n}=508) \\
n(\%)\end{array}$ & $\begin{array}{l}\mathrm{CU}(n=127) \\
n(\%)\end{array}$ & $p$ value & $\overline{O R}(95 \% \mathrm{CI})$ & $p$ value \\
\hline Anxiety (self-report, past 12 months) & $180(35.4 \%)$ & $83(65.4 \%)$ & $<0.001$ & $2.69(1.76-4.12)$ & $<0.001$ \\
\hline Depression (self-report, past 12 months) & $88(17.3 \%)$ & $41(32.3 \%)$ & $<0.001$ & $1.59(0.98-2.56)$ & 0.060 \\
\hline Sleep difficulties (past 12 months) & $166(32.7 \%)$ & $74(58.3 \%)$ & $<0.001$ & $2.19(1.43-3.36)$ & $<0.001$ \\
\hline
\end{tabular}

$C U$ chronic urticaria, $O R$ odds ratio

compared with wealthier, developed nations. Generally supporting this idea, prior research has shown that adults with lower socioeconomic status report more severe health impairments, poorer HRQoL, and lower life expectancy than those with higher socioeconomic status [23, 24]. Future research will need to verify this possibility empirically using appropriate cross-national comparisons. Differences in HRQoL exceeded minimally important differences for MCS and SF-6D score thresholds $[19,25,26]$. In the current study, CU respondents also had higher odds of experiencing anxiety and sleep difficulties than controls, which was consistent with previous research $[5,6]$. Additionally, CU has been associated with significantly greater odds of any physician visit, an ER visit, or a hospitalization [5], which are in agreement with results from the present study.
Likewise, impairment to work productivity and daily activities in this study were generally aligned with findings from recent international studies. Among respondents from the US, Europe, and Canada, overall work productivity impairment (measured with the WPAI) for those with CU was found to be $26.9 \%$ and activity impairment was reported at $32.8 \%$ [27]. Adults in Italy with $\mathrm{CU}$ were found to have overall work productivity impairment of $22.4 \%$ [28]. Collectively, a high degree of overall work productivity loss has implications for indirect costs, which were found in a previous study to range from US\$544.80 (France) to US\$1287.40 (Germany) per month [29]. This suggests the indirect costs of CU will also be sizeable in Brazil, although this would need to be confirmed with a future study. Therefore, better awareness and greater patient-physician discussion are needed to help reduce this burden on society. 
Table 5 Work and activity impairment among CU respondents relative to controls

\begin{tabular}{|c|c|c|c|c|c|}
\hline & \multicolumn{3}{|c|}{ Matched comparisons } & \multicolumn{2}{|c|}{$\begin{array}{l}\text { Regression estimates for } \\
\text { CU relative to controls }\end{array}$} \\
\hline & $\begin{array}{l}\text { Controls } \\
(n=508) \\
\text { Mean (SD) }\end{array}$ & $\begin{array}{l}\text { CU } \\
(n=127) \\
\operatorname{Mean}(S D)\end{array}$ & $p$ value & RR (95\% CI) & $p$ value \\
\hline Absenteeism (\%) $(n s=360 ; 95)$ & $7.9(19.1)$ & $7.6(12.0)$ & 0.879 & $0.89(0.50-1.58)$ & 0.697 \\
\hline Presenteeism $(\%)(n s=362 ; 96)$ & $20.2(27.0)$ & $36(29.0)$ & $<0.001$ & $1.61(1.20-2.17)$ & 0.002 \\
\hline Overall work impairment $(\%)(n s=360 ; 95)$ & $24.1(30.8)$ & $38.9(29.2)$ & $<0.001$ & $1.51(1.14-2.01)$ & 0.005 \\
\hline Activity impairment $(\%)(n s=508 ; 127)$ & $23.1(27.4)$ & $40.6(31.2)$ & $<0.001$ & $1.5(1.19-1.88)$ & 0.001 \\
\hline
\end{tabular}

$C I$ confidence interval, $C U$ chronic urticaria, $R R$ rate ratio, $S D$ standard deviation

Table 6 Higher numbers of health care visits among CU respondents relative to controls

\begin{tabular}{|c|c|c|c|c|c|}
\hline & \multicolumn{3}{|l|}{ Matched comparisons } & \multicolumn{2}{|c|}{$\begin{array}{l}\text { Regression estimates for } \\
\text { CU relative to controls }\end{array}$} \\
\hline & $\begin{array}{l}\text { Controls, }(n=508) \\
\text { Mean (SD) }\end{array}$ & $\begin{array}{l}\mathrm{CU},(n=127) \\
\text { Mean }(\mathrm{SD})\end{array}$ & $p$ value & RR (95\% CI) & $p$ value \\
\hline Total HCP visits & $5.2(7.9)$ & $12.3(13.1)$ & $<0.001$ & $1.95(1.51-2.51)$ & $<0.001$ \\
\hline GP visits & $1.0(2.5)$ & $1.4(2.5)$ & 0.098 & $1.48(1.00-2.18)$ & 0.050 \\
\hline Allergist visits & $0.1(0.4)$ & $0.9(1.8)$ & $<0.001$ & $8.02(4.64-13.86)$ & $<0.001$ \\
\hline Psychiatrist visits & $0.2(0.9)$ & $0.6(1.8)$ & 0.022 & $1.89(0.89-4.02)$ & 0.097 \\
\hline Psychologist/psychotherapist visits & $0.6(3.3)$ & $1.7(5.6)$ & 0.033 & $1.84(0.63-5.35)$ & 0.264 \\
\hline ER visits & $0.6(1.4)$ & $1.8(4.6)$ & 0.005 & $2.11(1.34-3.31)$ & 0.001 \\
\hline Hospitalizations & $0.2(0.7)$ & $0.5(1.2)$ & 0.013 & $1.57(0.87-2.84)$ & 0.138 \\
\hline
\end{tabular}

$C I$ confidence interval, $C U$ chronic urticaria, $E R$ emergency room, GP general practitioner, $H C P$ healthcare provider, $R R$ rate ratio, $S D$ standard deviation

Findings were also consistent with the limited available prior research from Brazil. For example, one study, which was conducted at an outpatient clinic in Sao Paulo, indicated that respondents with CU reported via the Dermatology Life Quality Index (DLQI) a negative impact on their ability to participate in daily and leisure activities, as well as experiencing uncomfortable symptoms (e.g., itching) and feelings of embarrassment from their condition [30]. Another study conducted in a Sao Paulo outpatient clinic assessed HRQoL using the SF-36 domain scores and the DLQI [31]. Although the aforementioned study was mainly concerned with comparing HRQoL among different types of $\mathrm{CU}$, regardless of type, CU was associated with significant impairment in work activities, daily activities, and high levels of fatigue [31]. This prior finding, along with our current findings, highlight the need for patients' HRQoL to be taken into account in devising strategies to better manage this condition.

\section{Limitations}

Overall, the findings should be considered in light of the limitations of the methodology. The NHWS may be less representative of the general population in Brazil with respect to 
socioeconomic status, as the survey tends to overrepresent higher-income insured respondents. This may have a greater impact in Brazil than in some other countries, as private supplemental insurance is provided as a benefit to employees, allowing greater access to care. Another limitation is that the analyses focused primarily on those currently treated with a prescription for $\mathrm{CU}$, which may have excluded some respondents who are currently experiencing hives but not receiving treatment for a variety of different reasons, such as a lack of access to allergy/dermatological care. This may have resulted in an underestimate of the prevalence of $\mathrm{CU}$. The type of urticaria was not available at the time of data collection. Also, in the current study, $\mathrm{CU}$ was used as a proxy indicator of CSU. This approach is consistent with prior research using the NHWS $[5,6,15]$ and justifiable given that over two-thirds of $\mathrm{CU}$ cases can be categorized as CSU cases [3]. Nevertheless, future research should aim to distinguish between the different types of urticaria. The survey is cross-sectional, and thus results do not indicate causal relationships or represent potential changes in these relationships over time.

\section{CONCLUSIONS}

The current study provides important new information about the point prevalence of $\mathrm{CU}$ in Brazil. The treated estimated prevalence appears somewhat lower than in studies of European and US adults. The current study also characterizes the psychological, physical, and economic costs of $\mathrm{CU}$ for patients living in Brazil. Many patients using prescription treatment still experience anxiety and sleep disturbances, poorer HRQoL, significant work and activity impairment, and heavy use of various healthcare resources. Thus, results substantiated the unmet need for better management of this condition in Brazil.

\section{ACKNOWLEDGEMENTS}

Sponsorship for this study was funded by Novartis Pharma AG, Switzerland and
Genentech. Article processing charges were funded by Novartis Pharma AG. All authors had full access to the data in this study and take complete responsibility for the integrity of the data and accuracy of the data analysis.

All named authors meet the International Committee of Medical Journal Editors (ICMJE) criteria for authorship for this manuscript, take responsibility for the integrity of the work as a whole, and have given final approval of the version to be published. The authors would like to acknowledge the editing assistance of Martine C. Maculaitis, $\mathrm{PhD}$, on behalf of Kantar Health, with funding from Novartis Pharmaceutical Corporation. All authors had full access to all of the data in this study and take complete responsibility for the integrity of the data and accuracy of the data analysis.

Disclosures. Maria-Magdalena Balp is an employee of Novartis Pharma AG, Switzerland. Nilcéia Lopes da Silva is an employee of Novartis Biociências S.A., São Paulo, Brazil. Haijun Tian is an employee of Novartis Pharmaceutical Corporation, USA. At the time this study was conducted, Jeffrey Vietri was employed by Kantar Health, which received funding from Novartis Pharma AG and Genentech for conducting the analysis and reporting on this study. Luis Felipe Ensina is a speaker and advisor for Novartis.

Compliance with Ethics Guidelines. All procedures performed in studies involving human participants were in accordance with the ethical standards of the Essex Institutional Review Board (Lebanon, NJ, USA), and the Pearl Institutional Review Board (Indianapolis, IN, USA) and with the 1964 Helsinki declaration and its later amendments or comparable ethical standards. For this type of study, formal consent is not required.

Data Availability. The datasets generated during and/or analyzed during the current study are not publicly available due to the proprietary nature of the NHWS database, but are available from the corresponding author on reasonable request. 
Open Access. This article is distributed under the terms of the Creative Commons Attribution-NonCommercial 4.0 International License (http://creativecommons.org/licenses/ by-nc/4.0/), which permits any noncommercial use, distribution, and reproduction in any medium, provided you give appropriate credit to the original author(s) and the source, provide a link to the Creative Commons license, and indicate if changes were made.

\section{REFERENCES}

1. Zuberbier T, Aberer W, Asero R, et al. The EAACI/ GA2LEN/EDF/WAO guideline for the definition, classification, diagnosis, and management of urticaria: the 2013 revision and update. Allergy. 2014;69:868-87.

2. Bernstein JA, Lang DM, Khan DA, et al. The diagnosis and management of acute and chronic urticaria: 2014 update. J Allergy Clin Immunol. 2014;133:1270-7.

3. Maurer $\mathrm{M}$, Weller $\mathrm{K}$, Bindslev-Jensen $\mathrm{C}$, et al. Unmet clinical needs in chronic spontaneous urticaria A GA2LEN task force report. Allergy. 2011;66:317-30.

4. Sabroe RA, Greaves MW. What is urticaria? Anatomical, physiological, and histological considerations and classification. In: Greaves MW, Kaplan A, editors. Urticaria and angioedema. New York: Marcel Dekker; 2004. p. 1-50.

5. Vietri J, Turner SJ, Tian H, Isherwood G, Balp M-M, Gabriel S. Effect of chronic urticaria on US patients: analysis of the National Health and Wellness Survey. Ann Allergy Asthma Immunol. 2015;115:306-11.

6. Balp M-M, Vietri J, Tian H, Isherwood G. The Impact of chronic urticaria from the patient's perspective: a survey in five European countries. Patient. 2015;8:551-8.

7. Gaig P, Olona M, Munoz Lejarazu D, et al. Epidemiology of urticaria in Spain. J Investig Allergol Clin Immunol. 2004;14:214-20.

8. Greaves M. Chronic urticaria. J Allergy Clin Immunol. 2000;105:664-72.

9. Zuberbier T, Balke M, Worm M, Edenharter G, Maurer M. Epidemiology of urticaria: a representative cross-sectional population survey. Clin Exp Dermatol. 2010;35:869-73.
10. Hallgren L. The prevalence of urticaria in the total population. Acta Allergol. 1972;27:236-40.

11. Grob JJ, Revuz J, Ortonne JP, Auquier P, Lorette G. Comparative study of the impact of chronic urticaria, psoriasis and atopic dermatitis on the quality of life. Br J Dermatol. 2005;152:289-95.

12. Staubach P, Eckhardt-Henn A, Dechene M, et al. Quality of life in patients with chronic urticaria is differentially impaired and determined by psychiatric comorbidity. Br J Dermatol. 2006;154:294-8.

13. DeLong LK, Culler SD, Saini SS, Beck LA, Chen SC. Annual direct and indirect health care costs of chronic idiopathic urticaria: a cost analysis of 50 nonimmunosuppressed patients. Arch Dermatol. 2008;144:35-9.

14. Murota $\mathrm{H}$, Kitaba $\mathrm{S}$, Tani M, et al. Impact of sedative and non-sedative antihistamines on the impaired productivity and quality of life in patients with pruritic skin diseases. Allergol Int. 2010;59:345-54.

15. Mendelson $\mathrm{MH}$, Bernstein JA, Gabriel S, et al. Patient-reported impact of chronic urticaria compared with psoriasis in the United States. J Dermatolog Treat. 2017;28:229-36.

16. Kamakura W, Mazzon JA. Critérios de estratificação e comparação de classificadores socieconômcios no Brasil (Socioeconomic stratification criteria and classification tools in Brazil). RAE. 2016;56:55-70.

17. Charlson ME, Pompei P, Ales KL, MacKenzie CR. A new method of classifying prognostic comorbidity in longitudinal studies: development and validation. J Chronic Dis. 1987;40:373-83.

18. Maruish ME. User's manual for the SF36v2 Health Survey. 3rd ed. Lincoln: Quality Metric; 2011.

19. Ware JE, Kosinski M, Turner Bowker DM, Gandek B. How to score version 2 of the SF-12v2 ${ }^{\circledR}$ Health Survey (with a supplement documenting SF-12 ${ }^{\circledR}$ Health Survey). Lincoln: QualityMetric; 2002.

20. Brazier J, Roberts J, Deverill M. The estimation of a preference-based measure of health from the SF-36. J Health Econ. 2002;21:271-92.

21. Brazier JE, Roberts J. The estimation of a preference-based measure of health from the SF-12. Med Care. 2004;42:851-9.

22. Reilly MC, Zbrozek AS, Dukes EM. The validity and reproducibility of a work productivity and activity impairment instrument. PharmacoEconomics. 1993;4:353-65.

23. Mielck A, Vogelmann M, Leidl R. Health-related quality of life and socioeconomic status: 
inequalities among adults with a chronic disease. Health Qual Life Outcomes. 2014;12:58.

24. Szwarcwald CL, da Mota JC, Damacena GN, Pereira TGS. Health inequalities in Rio de Janeiro, Brazil: lower health life expectancy in socioeconomically disadvantaged areas. Am J Public Health. 2011;101:517-23.

25. Norman GR, Sloan JA, Wyrwich KW. Interpretation of changes in health-related quality of life: the remarkable universality of half a standard deviation. Med Care. 2003;41:582-92.

26. Walters SJ, Brazier JE. Comparison of the minimally important difference for two health state utility measures: EQ-5D and SF-6D. Qual Life Res. $2005 ; 14: 1523-32$.

27. McBride D, Balp M, Abuzakouk M, et al. Assure-Csu: assessing the impact of chronic spontaneous/idiopathic urticaria on work productivity and activity. Value Health. 2016;19:A124.
28. Roccia A, Rigoni L, Cawson MR, McBride D, Canonica GW, Balp M. Assure-Csu: resource use and economic burden in patients with refractory chronic spontaneous/idiopathic urticaria in Italy. Value Health. 2016;19:A614.

29. McBride D, Abuzakouk M, Balp M, et al. Comparative analysis of indirect costs associated with chronic spontaneous/idiopathic urticaria-results from the Assure-Csu study in 7 countries. Value Health. 2016;19:A573.

30. Silvares $M$, Fortes $M$, Miot $H$. Quality of life in chronic urticaria: a survey at a public university outpatient clinic, Botucatu (Brazil). Rev Assoc Med Bras. 2011;57:565-9.

31. de Ue APF, Souza PK, Rotta O, Furlani WJ, Lima ARM, Sabbag DSOV. Quality of life assessment in patients with chronic urticaria. An Bras Dermatol. 2011;86:897-904. 